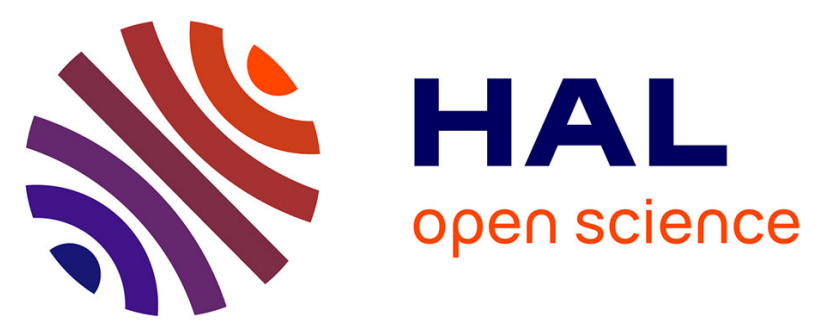

\title{
Bottom-Up Electrochemical Fabrication of Conjugated Ultrathin Layers with Tailored Switchable Properties
}

Verena Stockhausen, van Quyen Nguyen, Pascal G.P. Martin, Jean Christophe Lacroix

\section{- To cite this version:}

Verena Stockhausen, van Quyen Nguyen, Pascal G.P. Martin, Jean Christophe Lacroix. Bottom-Up Electrochemical Fabrication of Conjugated Ultrathin Layers with Tailored Switchable Properties. ACS Applied Materials \& Interfaces, 2017, 9 (1), pp.610-617. 10.1021/acsami.6b08754 . hal-01821774

\section{HAL Id: hal-01821774 \\ https: / hal-univ-paris.archives-ouvertes.fr/hal-01821774}

Submitted on 25 Jun 2018

HAL is a multi-disciplinary open access archive for the deposit and dissemination of scientific research documents, whether they are published or not. The documents may come from teaching and research institutions in France or abroad, or from public or private research centers.
L'archive ouverte pluridisciplinaire HAL, est destinée au dépôt et à la diffusion de documents scientifiques de niveau recherche, publiés ou non, émanant des établissements d'enseignement et de recherche français ou étrangers, des laboratoires publics ou privés. 
This document is confidential and is proprietary to the American Chemical Society and its authors. Do not copy or disclose without written permission. If you have received this item in error, notify the sender and delete all copies.

\section{Bottom-Up Electrochemical Fabrication of Conjugated Ultrathin Layers with Tailored switchable properties}

\begin{tabular}{|r|l|}
\hline Journal: & ACS Applied Materials \& Interfaces \\
\hline Manuscript ID & am-2016-08754q \\
\hline Manuscript Type: & Article \\
\hline Complete List of Authors: & $\begin{array}{l}\text { Stockhausen, Verena; University Paris 7-Debis Diderot, Chimie } \\
\text { Nguyen, Van ; University Paris 7-Denis Diderot, ITODYS } \\
\text { Martin, Pascal; University Paris 7, Chemistry } \\
\text { Lacroix, Jean-Christophe; University Paris 7-Denis Diderot, ITODYS }\end{array}$ \\
\hline
\end{tabular}

\section{SCHOLARONE \\ Manuscripts}




\title{
Bottom-Up Electrochemical Fabrication of Conjugated Ultrathin Layers with Tailored switchable properties
}

\author{
Verena Stockhausen ${ }^{1}$, Van Quyen Nguyen ${ }^{1,2}$, Pascal Martin ${ }^{1}$, Jean Christophe Lacroix ${ }^{1 *}$ \\ ${ }^{1}$ Université Paris Diderot, Sorbonne Paris Cité, ITODYS, UMR 7086 CNRS, 15 rue Jean- \\ Antoine de Baïf, 75205 Paris Cedex 13, France. \\ ${ }^{2}$ Department of Advanced Materials Science and Nanotechnology, University of Science and \\ Technology of Hanoi (USTH), Vietnam Academy of Science and Technology, 18 Hoang Quoc \\ Viet, Cau Giay, Hanoi, Vietnam
}

\begin{abstract}
KEYWORDS. Bottom-up approach, nano-electrochemistry, ultrathin film, $\pi$-conjugated material, diazonium grafting, molecular electronics.
\end{abstract}

\begin{abstract}
In this work, we develop a Bottom-Up Electrochemical Fabrication process of Conjugated Ultrathin Layers with Tailored switchable properties. To do so, we use ultrathin layers of covalently grafted oligo(bisthienylbenzene) (oligo(BTB)) as a switchable organic electrodes and perform 3,4-ethylenedioxythiophene (EDOT) oxidation on such organic layer. Adding only $3 \mathrm{~nm}$ of EDOT moieties (5 to 6 units) completely changes the switching properties of the layer without changing the surface concentration of the grafted electroactive species. As a consequence, a range of new materials, with tunable interfacial properties, is created through this bottom-up electrochemical process. They consist of oligo(BTB)-oligo(EDOT) di-block oligomers of various relative length grafted covalently on the underlying electrode. As an
\end{abstract}


important result these ultrathin films retain reversible redox on/off switching and their switching potential can be finely tuned between 0.6 and $-0.3 \mathrm{~V} / \mathrm{SCE}$ despite an overall thickness that remains below $11 \mathrm{~nm}$.

\section{INTRODUCTION}

Bottom-up approach is one of the heart pieces of modern material science and provides an enormous creativity in its use as tool for the fabrication of an almost undetermined choice of smart materials $^{1-6}$,interfaces ${ }^{4,6-14}$ and nanoelectronic devices ${ }^{15-24}$. Ultrathin films of conjugated oligomers grafted on surfaces from diazonium salt reduction are of particular interest for the fabrication of molecular electronic devices ${ }^{17,25-27}$. Indeed they allow the fabrication in high yield of robust molecular junctions using CMOS compatible processes ${ }^{25-26}$. Among such layers, ultrathin films combining thiophene and EDOT units exhibit unique on/off switching of their transport properties in electrochemical environment ${ }^{28-31}$. Insulating behavior is observed below an intrinsic film commutation potential whereas above this potential, they become conductive. As a consequence, reversible redox probes with an $\mathrm{E}^{0}$ below this intrinsic film commutation potential exhibit an anodic peak shifted towards higher potential and no cathodic peak, while reversible redox probes with an $\mathrm{E}^{0}$ above the film commutation potential exhibit the same redox behaviour as on bare electrodes ${ }^{28-29}$. The film commutation potential depends on the molecular structure of the grafted oligomers and incorporating EDOT in the molecular backbone decreases the layer switching potential ${ }^{28,30}$. Overall, such systems combine the advantages of conductive oligomers to those of diazonium based layers, i.e. fine control of the film thickness in the 2 to 20 $\mathrm{nm}$ range, ability to generate robust, pinhole free and electroactive layers, two redox states of different conductivity ${ }^{26}$. As a consequence they can be seen as switchable organic electrodes. 
In this work we investigate a bottom-up electrochemical process based on the electrochemical oxidation of irreversible redox systems on such a switchable organic electrodes, namely oligo(bisthienylbenzene) (BTB) layer. In doing so, we wish to create new ultrathin layers with tunable properties. For this purpose, we chose to study EDOT oxidation, a monomer whose oxidation is irreversible, gives unstable EDOT radical cations and yields on a bare electrode to PEDOT deposition. As EDOT oxidation potential is located beyond the switching potential of the grafted oligo(BTB), it will take place on a p-doped organic conductive electrode, that is a layer in which oligo(BTB) radical cations are already generated. As a consequence, two types of reactive radical cations will be created in the vicinity of the electrode and we will investigate the outcome of their chemical coupling and the resulting electrode modification. In doing so we wish to evaluate if it is possible to extend the ways to combine the advantages of conductive oligomers to those of diazonium based layers using a low cost bottom up nano-electrochemical process.

Scheme 1 displays the two possible scenarios and materials that can be expected, depending on the concentration of the EDOT radical cations generated in the vicinity of the oligo(BTB) electrode and their relative reactivity towards oligo(BTB) radical cations.

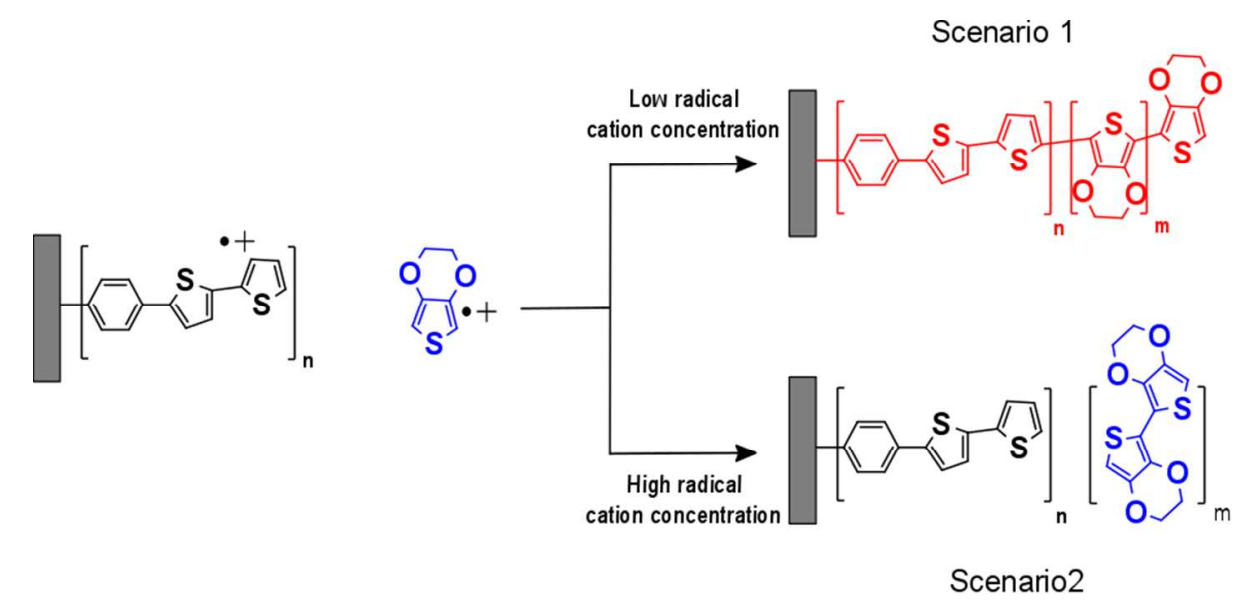


Scheme 1: Alternative scenarios that can be anticipated when performing EDOT oxidation on an oligo(BTB) layer. In scenario 1, a new material is generated by covalent attachement of EDOT on oligo(BTB). In scenario two, Oligo(BTB) layer is covered by PEDOT and an interface exists between the two materials

First, at low EDOT radical cation concentration (i.e; low EDOT oxidation current density), EDOT radical cations can couple covalently to the grafted layer and thus extend the aromatic chain and create new block oligomers with new properties (Scenario 1). In this case, a new material is generated and its electrochemical and interfacial properties differ from those of the initial BTB layer.

Alternatively, at high current densities, EDOT radical cations may prefer to react with each other and form oligomers in solution or even a polymer. It can then precipitate onto the first layer, yielding a double layer structure by physisorption (Scenario 2). In this case, two different materials are deposited in a bilayer structure with a specific interface separating the two materials. As the BTB layer is not modified in this scenario, it keeps its electrochemical properties. As BTB potential switch is above that of PEDOT, BTB will command the electrochemical properties of the physisorbed PEDOT layer.

\section{EXPERIMENTAL METHODS}

Chemicals: 1-(2-bisthienyl)-4-aminobenzene were synthesized according to published procedures $^{28,} 32$. All chemicals were used as received. Ferrocene $(\mathrm{Fc})$, decamethylferrocene $(\mathrm{DmFc})$ and were purchased from Sigma Aldrich. Tert-butyl nitrite (tBuO-NO) was purchased from Aldrich. Lithium perchlorate $\left(\mathrm{LiClO}_{4}\right)$ and tetrabutylammonium tetrafluoroborate $\left(\mathrm{Bu}_{4} \mathrm{NBF}_{4}\right)$ from Aldrich were used as supporting electrolyte at $0.1 \mathrm{M}$ concentration in acetonitrile (ACN). 3,4-ethylenedioxythiophene (EDOT) was from Bayer. 
Electrochemical deposition of the oligo(BTB) layer: The in situ formation of the diazonium cation from 1-(2-bisthienyl) precursor was performed without any acid in the solution, by adding tert-butyl nitrite $(\mathrm{tBuO}-\mathrm{NO})^{28,}$ 33-35 Briefly, an acetonitrile solution containing of 1-(2bisthienyl)-4-aminobenzene $(0.5 \mathrm{mM})$ and $\mathrm{Bu}_{4} \mathrm{NBF}_{4}(0.1 \mathrm{M})$ as supporting electrolyte was prepared and degassed by argon bubbling for at least 10 min. Following that, tBuO-NO was added in excess to the solution (30 equivalents). As the reaction between amine function and tertbutyl nitrite is relatively slow, grafting was only started after 5 minutes incubation time. BTB layer deposition was performed using multicyle voltammetry between $0.4 \mathrm{~V} / \mathrm{SCE}$ and -0.4 V/SCE on glassy carbon electrodes as well as on gold stripes $(20 \mu \mathrm{m}$ wide and $5 \mathrm{~mm}$ long). The thickness of the deposited layer was measured using tapping mode AFM and was set to $\sim 8 \mathrm{~nm}$. Each electrode was then characterized in acetonitrile containing $1 \mathrm{mM}$ ferrocene and $0.1 \mathrm{M}$ $\mathrm{LiClO}_{4}$

Electrochemical oxidation of EDOT on the oligo(BTB) organic electrode: Electrodes previously functionalized by oligo(BTB) were sonicated in $\mathrm{ACN}$ for 10 minutes and plunged in a solution containing $2 \times 10^{-2} \mathrm{M}$ EDOT. Cyclic voltammograms were performed while the potential window was adjusted in order to obtain oxidation charges turning around $0.3 \mathrm{mC} / \mathrm{cm}^{2}$, corresponding to a maximal theoretical deposition thickness of $2 \mathrm{~nm}$ for each EDOT oxidation cycle (or around 3-4 moieties, considering a size of $0.6 \mathrm{~nm}$ per EDOT unit). After each oxidation cycle, the electrode was thoroughly rinsed with $\mathrm{ACN}$ and electrochemically characterized in electrolyte solution $\left(0.1 \mathrm{M} \mathrm{LiClO}_{4}\right.$ in $\left.\mathrm{ACN}\right)$, without any redox probe, at a scan rate of $10 \mathrm{~V} / \mathrm{s}$ (with ohmic drop compensation). Then, voltammograms in presence of Fc and DmFc were recorded using the same modified electrode. This procedure (EDOT deposition on the organic 
electrode, rinsing characterisation in $\mathrm{Fc}$, and $\mathrm{DmFc}$, and in redox probe free solution) was repeated several times.

AFM characterization: AFM measurements were performed on a Molecular Imaging system (picoscan 5500). AFM images are recorded in tapping mode with tapping tip from Budgetsensor (AFM tap 300G, resonant freq $300 \mathrm{kHz}$, force constant 40nN/m). Blank studies were first realized on bare Au microelectrode in order to measure the thickness of Au stripes. The thickness of the grafted layer is then determined by subtracting the thickness of the Au bottom electrode ${ }^{26,36}$.

\section{RESULTS AND DISCUSSION}

The voltammograms of EDOT oxidation onto the BTB layer are shown in Figure 1a, where the number of cycles used is indicated. EDOT oxidation onset starts at $0.8 \mathrm{~V} / \mathrm{SCE}$ and is as expected irreversible. Successive oxidation cycles show that this onset shifts slightly to higher values as the BTB layer is modified by EDOT moieties deposition. In order to generate a small amount of EDOT radical-cations, the current density has been restricted to be below 0.3 $\mathrm{mA} / \mathrm{cm}^{2}$. EDOT oxidation is here performed at the threshold of the EDOT oxidation signal which can reach current as high as $20 \mathrm{~mA} / \mathrm{cm}^{2}$ with such EDOT concentration. After each oxidation cycle, the electrode was thoroughly rinsed with $\mathrm{ACN}$ and electrochemically characterized in electrolyte solution $\left(0.1 \mathrm{M} \mathrm{LiClO}_{4}\right.$ in $\left.\mathrm{ACN}\right)$, with Fe then with $\mathrm{DmFc}$ redox probe. Voltammograms of Fc and DmFc were recorded using the same modified electrode. The electrochemical responses of these two redox probes are thus an indication of the modifications of the layer electrochemical properties, induced by each EDOT deposition cycle. This procedure (EDOT deposition on the organic electrode, rinsing characterisation in $\mathrm{Fc}$, and $\mathrm{DmFc}$,) was 
repeated several times in order to monitor the progressive evolution of the transport properties of the modified electrode.

Figure $1 \mathrm{~b}$ and $1 \mathrm{c}$ illustrate the evolution of $\mathrm{Fc}$ and $\mathrm{DmFc}$ voltamograms on such BTB based organic electrodes as a function of the number of EDOT oxidation cycles used to modify the initial BTB electrode.
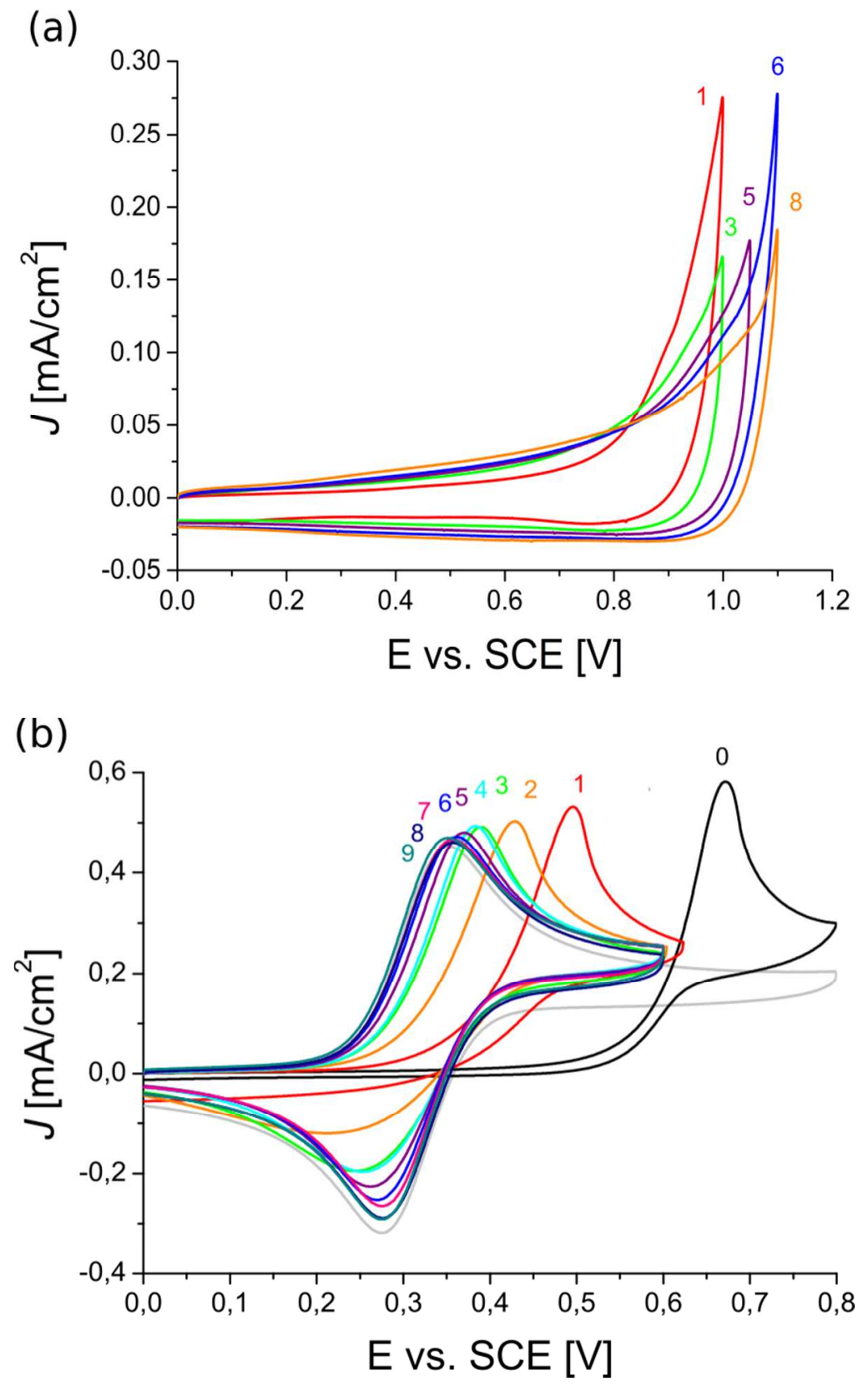
(c)

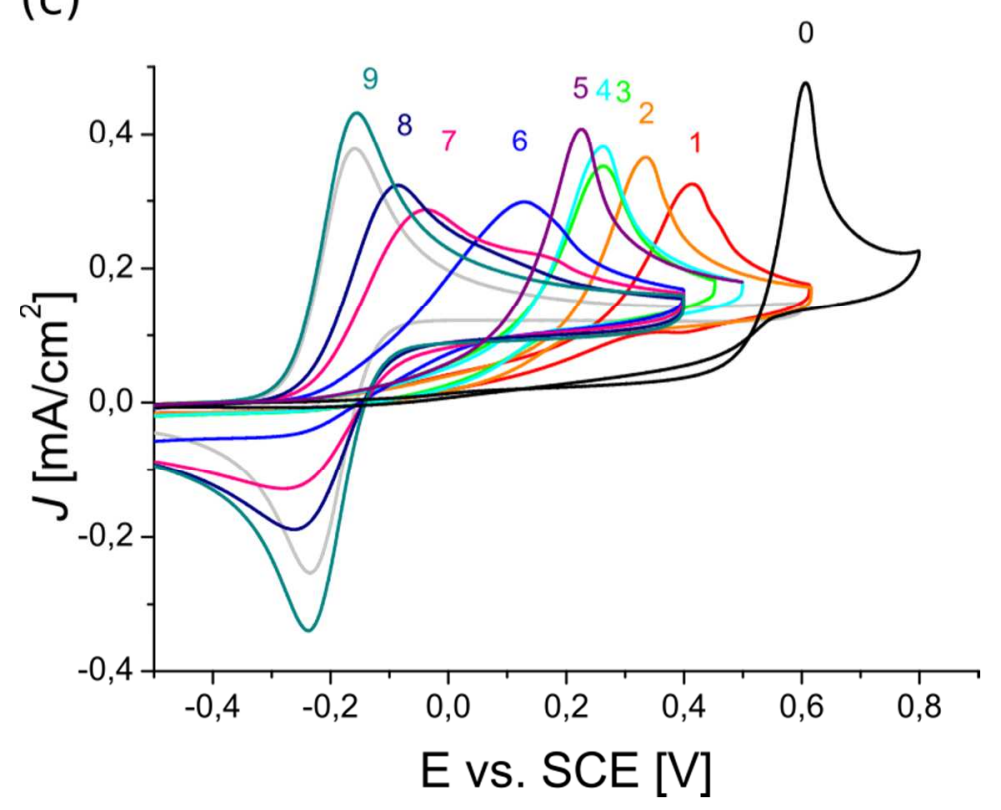

Figure 1: (a) EDOT oxidation on a oligo(BTB)-modified GC electrode in ACN with EDOT ( $2 \mathrm{x}$ $10^{-2} \mathrm{M}$ ) and $\mathrm{LiClO}_{4}(0.1 \mathrm{M})$; (b) Response of ferrocene on the oligo(BTB)/EDOT modified electrodes $(\mathrm{Fc} ; 1 \mathrm{mM})$ with $\mathrm{LiClO}_{4}(0.1 \mathrm{M})$ as supporting electrolyte in $\mathrm{ACN}$, after cycling in EDOT solution $\left(2 \times 10^{-2} \mathrm{M}\right) .0$ represents Fc response prior to EDOT cycling, 1-9 represent the number of deposition cycles in EDOT solution used for modifying the BTB electrode. (c) Response of decamethylferrocene on the same oligo(BTB)/EDOT modified electrodes (dmFc; 1 $\mathrm{mM})$ with $\mathrm{LiClO}_{4}(0.1 \mathrm{M})$ as supporting electrolyte in $\mathrm{ACN}$, after cycling in EDOT solution $(2 \mathrm{x}$ $\left.10^{-2} \mathrm{M}\right) .0$ represents electrode response prior to EDOT cycling, 1-9 represent the number of deposition cycles. Scan rate: $0.1 \mathrm{~V} / \mathrm{s}$.

Ferrocene oxidation signal on the initial oligo(BTB) layer is curve labelled " 0 ". As ferrocene redox potential is below the switching potential of the oligo(BTB) layer, it has a typical diode like signature, i.e. no current is observed at $0.3 \mathrm{~V} / \mathrm{SCE}$ but ferrocene oxidation peak is shifted to positive values while no reduction peak associated to the ferricinium reduction, is observed during backward scan. Such behavior indicates that the oligo(BTB) film is pinhole free and switches from insulating to conductive at $0.65 \mathrm{~V} / \mathrm{SCE}^{29-30}$. 
After the first oxidation cycle in presence of EDOT, the ferrocene signal on the new electrode is labelled " 1 " in Figure 1b. A typical diode like signature is still observed (Figure 1b curve 1), which indicates that the new electrode still switches from an insulating to a conductive state. However, the anodic peak potential is lowered compared to that observed on an unmodified BTB film. Upon further cycling, the anodic peak potential decreases more and after the third cycle, an emerging cathodic peak, corresponding to $\mathrm{Fc}^{+}$reduction, is observed. The intensity of this cathodic peak increases progressively while the layer is modified during 3rd to 7th cycle of EDOT oxidation. Simultaneously, the peak separation between anodic and cathodic peak, which is a measure of the reversible redox probe heterogeneous electron transfer kinetic constant, decreases. From the seventh cycle on, ferrocene shows reversible behaviour on the new organic electrode with $\Delta E_{p}$ close to $60 \mathrm{mV}$ and does not significantly changes upon further EDOT oxidation cycles.

DmFc redox probe was also used to report on the transport properties of the layer after each EDOT oxidation cycle. The voltammograms obtained on DmFc are depicted in Figure 1c. They show a preserved diode-like behavior until the sixth cycle of EDOT oxidation, while after that, a growing cathodic signal appears, attributed to $\mathrm{DmFc}^{+}$reduction on the modified electrode. Simultaneously $\Delta E_{p}$ starts to get measurable at that point and decreases after each EDOT oxidation cycle and finally stabilises at $60 \mathrm{mV}$ after nine successive EDOT cycles. After cycle 9, total reversibility is achieved also for DmFc. It is noticeable that at this moment, the film has become transparent towards Fc and DmFc.

At that point, a first intermediate conclusion can be drawn. EDOT oxidation on oligo(BTB) layer chemically modifies the pristine oligo(BTB) layer and changes its transport properties. The shape of the electrochemical response of Fc and Dmfc clearly demonstrates that 
the new electrodes still switch from an insulating to a conductive state. The switching potential of EDOT modified BTB electrodes can be easily tuned from $0.65 \mathrm{~V} / \mathrm{SCE}$ to below $-0.3 \mathrm{~V} / \mathrm{SCE}$ and at any intermediate values by careful control of the EDOT oxidation process. As a consequence, one can easily reach an intermediate situation in which EDOT modified oligo(BTB) electrode is transparent towards ferrocene, while a diode like behaviour is still observed with decamethylferrocene. This behaviour is expected from Scenario 1 (covalent grafting of oligo (EDOT) block on oligo(BTB)) as described in scheme 1 and is not compatible with scenario 2 in which the oligo(BTB) layer retain its switching potential. The differenciated $\Delta E_{p}$ evolution of $\mathrm{Fc}$ and $\mathrm{DmFc}$ redox probes associated to the pinhole free compact oligo(BTB) layer (observed in electrochemistry and when metal evaporation is directly performed on the layer) exclude PEDOT polymer growth through pinholes of the oligo(BTB) layer ${ }^{26,36}$. As an important result, these experiments demonstrate that it is possible to tune the switching potential of the layer from its initial value of $0.65 \mathrm{~V} / \mathrm{SCE}$ to below $-0.3 \mathrm{~V} / \mathrm{SCE}$ by using the procedure described above.

This distinctive evolution of the two redox probes signal is to our belief unique and has never been reported elsewhere. It is thus detailed in Figure 2 and Figure SI1-X where $\mathrm{X}$ designates the number of EDOT oxidation cycles used to modify the BTB layer. Each figure also contains the electrochemical response of $\mathrm{Fc}$ and $\mathrm{DmFc}$ on a bare $\mathrm{GC}$ electrode and on the pristine oligo(BTB) film. By comparing both probe responses in one graph, we nicely see how their respective electrochemical signal gradually changes. After 1 cycle of EDOT oxidation (Figure SI1-1), both redox probes show still irreversible behaviour while after cycle 2 (Figure 2a), Fc already starts to exhibit a cathodic wave. After cycle 4, Fc finally starts to behave like on bare electrode (Figure 2b) and does not shift any more from cycle 6 on (Figure 2c), indicating 
that now, Fc is quasireversible on this film. In the meantime, DmFc still preserves its diode-like behavior and only after cycle 7 (Figure SI1-7), a cathodic peak appears but the $\Delta E_{p}$ is still superior to bare electrode, indicating that the electrode remains partially blocked ${ }^{37}$. After cycle 9 (Figure 2d), both redox probes show reversible behaviour onto the modified electrode at the same $E_{0}$ than on bare electrodes. Sonication in ACN during 15 minutes did not modify film responses, which is a further indication for covalent attachment of EDOT moities and thus strongly points to Scenario 1 (scheme 1).

(a)

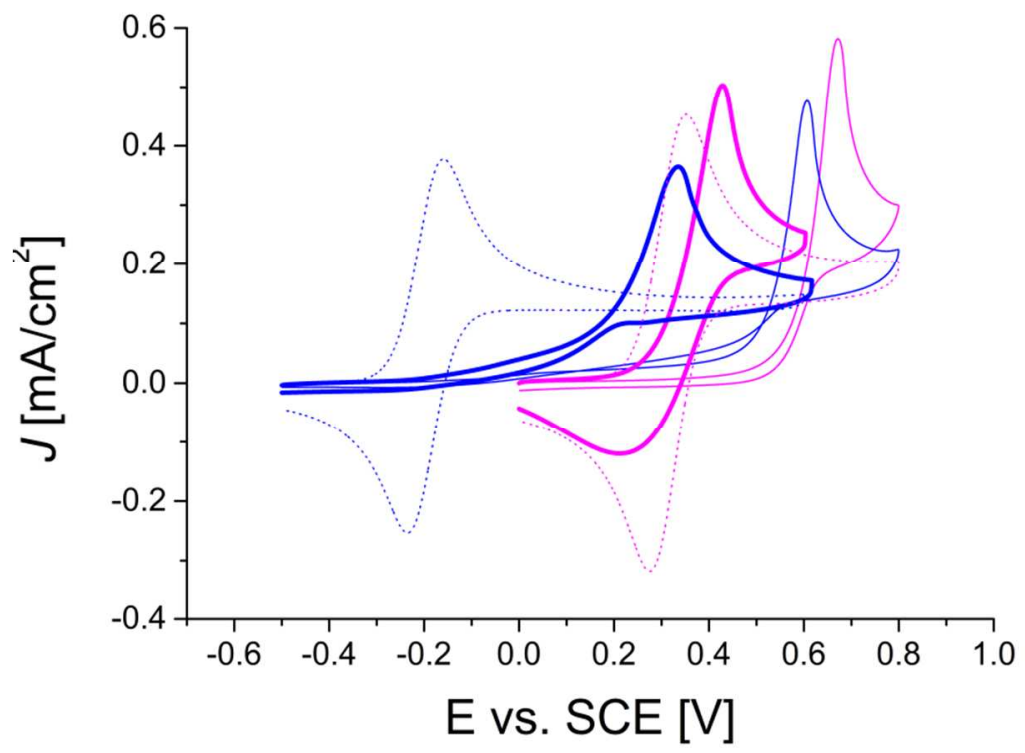



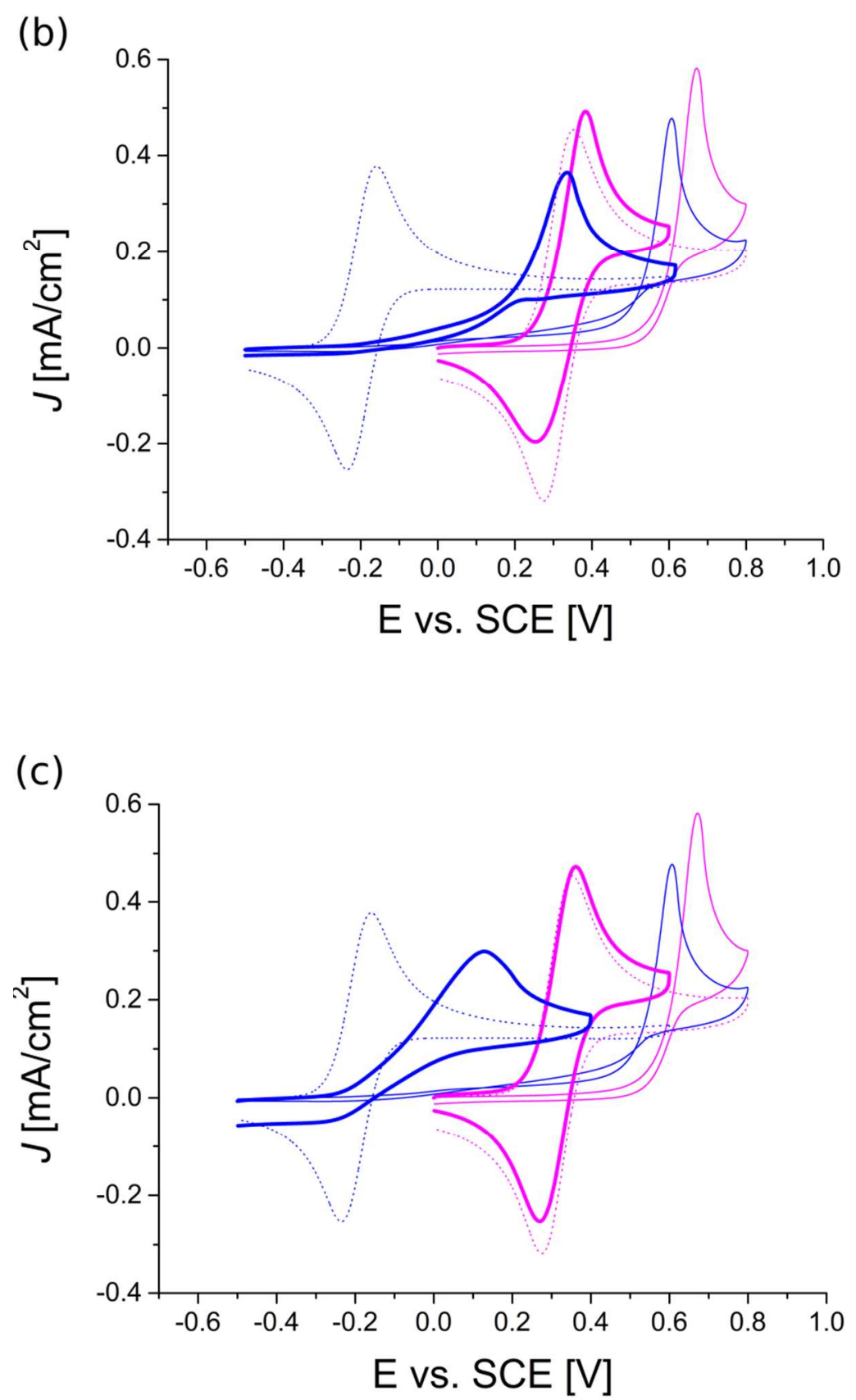


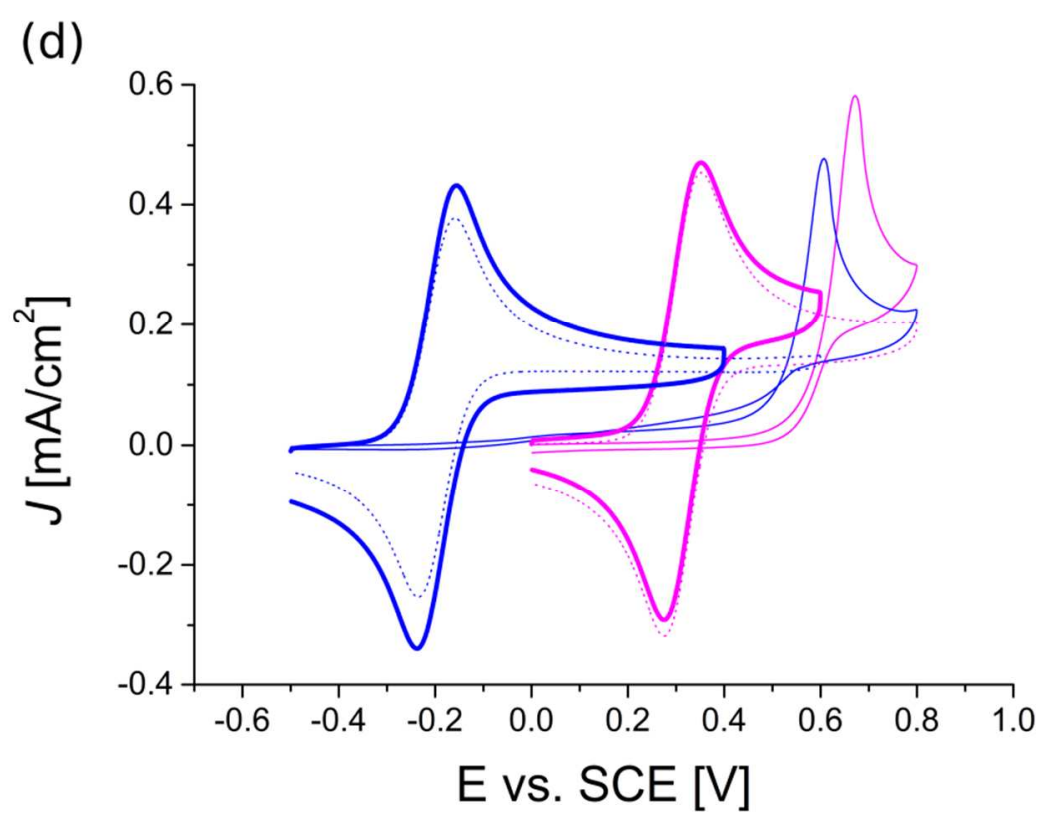

Figure 2: Comparison of Fc (pink line) and DmFc (blue line) (both at $1 \mathrm{mM}$ concentration in ACN with $0.1 \mathrm{M} \mathrm{LiClO}_{4}$ as supporting electrolyte) response on oligo(BTB) modified electrodes (thin solid line) and after cycling in EDOT solution ( $2 \times 10-2 \mathrm{M})$ (dashed line) with redox probe response on bare glassy carbon electrode (thick solid line). (a) After 2 EDOT overgrating cycles, (b) after 4 EDOT overgrafting cycles (c) after 6 EDOT overgrafting cycles, (d) after 9 overgrafting cycles. Scan rate: $0.1 \mathrm{~V} / \mathrm{s}$.

To characterize further the film modification, electroactivity of the EDOT-modifiedBTB-electrode was recorded in ACN at $10 \mathrm{~V} / \mathrm{s}$ with IR drop compensation(Figure 3a) after each EDOT oxidation cycle, and compared to that of an unmodified oligo(BTB) electrode. This electroactivity shows small anodic and cathodic peaks shifting progressively towards less positive values upon successive EDOT oxidation cycle. Initial anodic peak for BTB is above $0.75 \mathrm{~V} / \mathrm{SCE}$ then shifts to $0.55,0.50,0.35,0.25$ and $0.15 \mathrm{~V} / \mathrm{SCE}$ after $13,5,7$ and 8 EDOT oxidation cycles, respectively. Cathodic current peak follows the same tendency and the anodic current density onset also decreases to lower potential upon successive EDOT oxidation cycle. 
These measurements confirm that the switching potential of the EDOT modified oligo(BTB) electrode is progressively lowered.
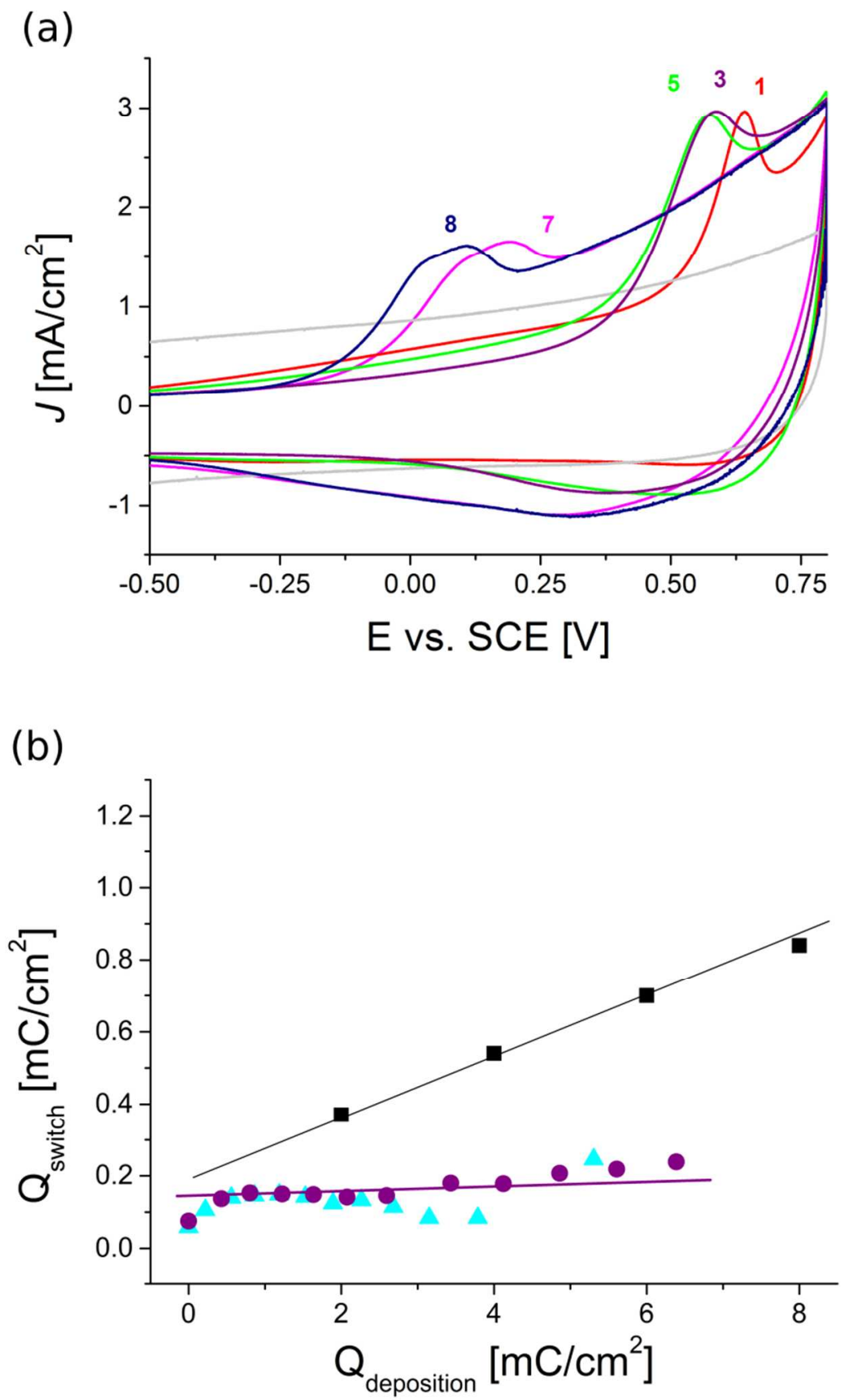

Figure 3: a) Electroactivity after 1, 3, 5, 7 and 8 EDOT oxidation cycle respectively on BTBmodified GC electrode. CVs are recorded in $\mathrm{ACN}$ with $\mathrm{LiClO}_{4}(0.1 \mathrm{M})$ as supporting electrolyte. Grey line is bare electrode, scan rate: $10 \mathrm{~V} / \mathrm{s}$ (ohmic drop correction). (b) Evolution of $\mathrm{Q}_{\text {switch }}$ as a 
function of $\mathrm{Q}_{\text {deposition. }}$ Colours correspond to two different electrodes, black squares represent PEDOT deposition on bare electrode.

By integration of the $\mathrm{CV}$, the amount of charge observed for doping the deposited layer $\left(\mathrm{Q}_{\text {switch }}\right)$ as a function of charge applied during EDOT anodic deposition $\left(\mathrm{Q}_{\text {deposition }}\right)$ was determined. $\mathrm{Q}_{\text {switch }}$ was plotted against $\mathrm{Q}_{\text {deposition }}$ (Figure $3 \mathrm{~b}$ blue and magenta points) and compared to the results obtained when anodic polymerisation of EDOT is performed on a bare electrode (Figure 3b black points), without underlying oligo(BTB) layer. On a bare GC electrode, a linear increase of $\mathrm{Q}_{\text {switch }}$ with a $\mathrm{Q}_{\text {deposition }}$ is observed with a ratio close to 10 between $\mathrm{Q}_{\text {deposition }}$ and $\mathrm{Q}_{\text {switch }}{ }^{38-39}$. Such behaviour has already been observed for many conducting polymers. When EDOT oxidation is performed on a oligo(BTB) layer, the evolution of $\mathrm{Q}_{\text {switch }}$ is clearly different. It does not significantly increase upon the successive EDOT deposition cycle and remains around $0.2 \mathrm{mC} / \mathrm{cm}^{2}\left(\Gamma=2.10^{-9} \mathrm{~mol} / \mathrm{cm}^{2}\right)$ when $Q_{\text {deposition }}$ increases. However when Qdeposition gets above $6.5 \mathrm{mC} / \mathrm{cm}^{2}$, the expected curve for PEDOT polymerisation is obtained as can be seen in figure SI3. This result is a very strong indication that covalent grafting of few EDOT units had taken place on the BTB oligomers yielding to a block oligo(BTB)-oligo(EDOT) that can be oxidized at a lower potential compared to oligo(BTB). (Note also that under application of this charge, a PEDOT film of around $30 \mathrm{~nm}$ would be formed if it was performed on a bare electrode.)

In order to measure the thickness variation of the oligo(BTB) film upon EDOT oxidation, similar experiments were performed on gold stripes, $42 \pm 0.5 \mathrm{~nm} \mathrm{~nm}$ thick, e-beam deposited on $\mathrm{Si} / \mathrm{SiO}_{2}$ substrates. This allows to use AFM for thickness measurements at each step of the electrochemical bottom up process. As the stripes exhibit a very small size of $20 \mu \mathrm{m}$ per $5 \mathrm{~mm}$, the electrochemical response of ferrocene is close to that obtained on an ultramicroelectrode (UME) with stationary plateau currents observed when ferrocene is oxidized to ferricinium. ${ }^{28-29}$ 
Figure 4a shows the AFM profile of three different films generated on gold stripes while Figure $4 \mathrm{~b}$ and $4 \mathrm{c}$ show the behaviour of ferrocene and decamethylferrocene on these electrodes. The first one is a oligo(BTB) electrode and Figure 4a reveals that the oligo(BTB) exhibits an average thickness of 7.5-8 nm with a root mean square roughness of $0.7 \mathrm{~nm}$. As expected on the gold/BTB electrode, the electrochemical oxidation of Fc and DmcFe is shifted to $0.7 \mathrm{~V} / \mathrm{SCE}$ whereas on a bare electrode, a plateau like current at $0.3 \mathrm{~V} / \mathrm{SCE}$ and $-0.2 \mathrm{~V} / \mathrm{SCE}$ is observed. Note also that the value of the diffusion limited current is the same on the bare and all modified electrodes.

The oligo(BTB) electrode was then modified by EDOT oxidation, generating a new modified electrode labelled BTB-EDOT1. The thickness of the organic layer is close to $9 \mathrm{~nm}$ and the roughness of this electrode appears almost the same as that of the initial oligo(BTB) electrode. However, the Fc and response on this electrode is significantly different with an onset for ferrocene oxidation at $0.3 \mathrm{~V} / \mathrm{SCE}$, a current rising on a larger potential range and a plateau current obtained only at $0.5 \mathrm{~V} / \mathrm{SCE}$. This result shows that despite a minimal amount of EDOT grafted on the BTB oligomers (around one nm thickness increase, i.e. 1 or 2 EDOT moieties), the switching potential of the new BTB-EDOT1 electrode decreases sharply from its initial value. This result is compatible with that observed when films are generated from new diazonium cations, derived from 2-(4-aminophenyl)-3,4-ethylenedioxy-thiophene and various aminofunctionalized $\pi$-conjugated oligomers incorporating 3,4-ethylenedioxythiophene (EDOT) and thiophene units ${ }^{30}$.

A second electrode labelled BTB-EDOT2 was then generated and studied. Its thickness is now 9-10 nm with a roughness of $0.9 \mathrm{~nm}$. EDOT block of the electrode is thus only 2 to $3 \mathrm{~nm}$ which implies that the EDOT block grafted on the oligo(BTB) electrode consists of only 4 to 6 
EDOT units. Fc signal on this electrode is at the same potential and has the same shape as on a bare gold stripe, showing that BTB-EDOT2 electrode has a switching potential below the standard redox potential of ferrocene. On the contrary, DmFc signal is still shifted to higher potential when compared to its position on a bare gold stripe. Onset of DmFc oxidation signal is now at $0.0 \mathrm{~V} / \mathrm{SCE}$ and plateau current is reached at $0.2 \mathrm{~V} / \mathrm{SCE}$ which is as expected below the standard redox potential of Fc.

Finally, a third electrode labelled BTB-EDOT3 was generated. The thickness of the organic layer is $10-11 \mathrm{~nm}$ with an average roughness of $1.1 \mathrm{~nm}$ and this electrode is transparent for ferrocene but not yet fully transparent for $\mathrm{DmFc}$ as $\mathrm{DmFc}$ oxidation onset is seen at -0.1 V/SCE with plateau current reached at $0 \mathrm{~V} / \mathrm{SCE}$. Thickness measurements indicate that the oligo(EDOT) block grafted on the initial oligo(BTB) units is only 3-4 nm thick that is close to 6 to 8 EDOT units.

(a)

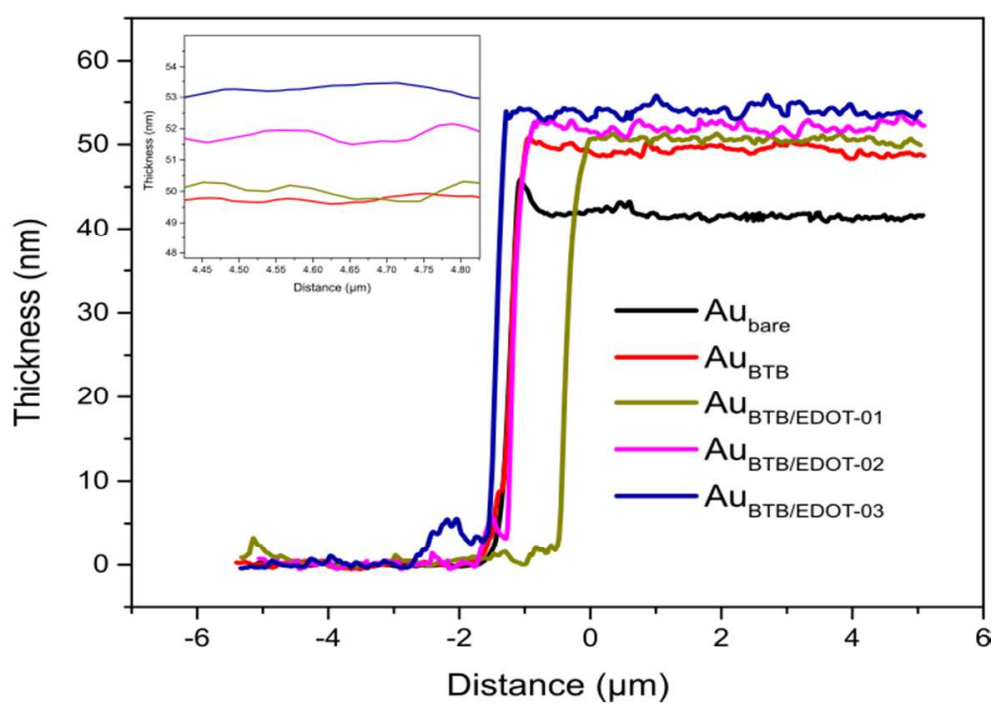




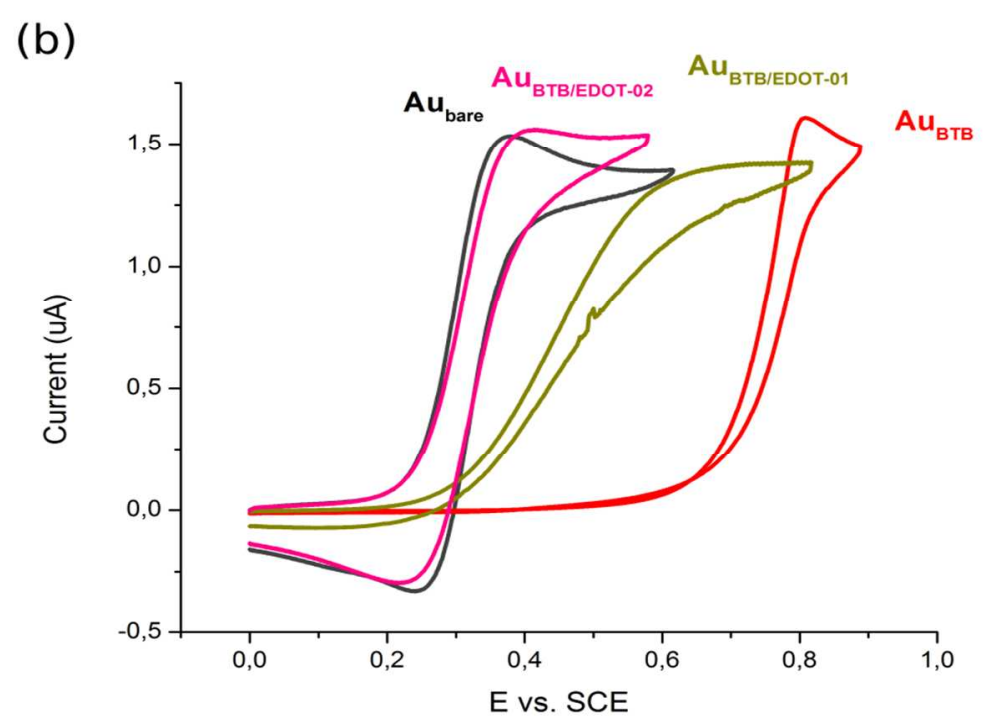

(c)

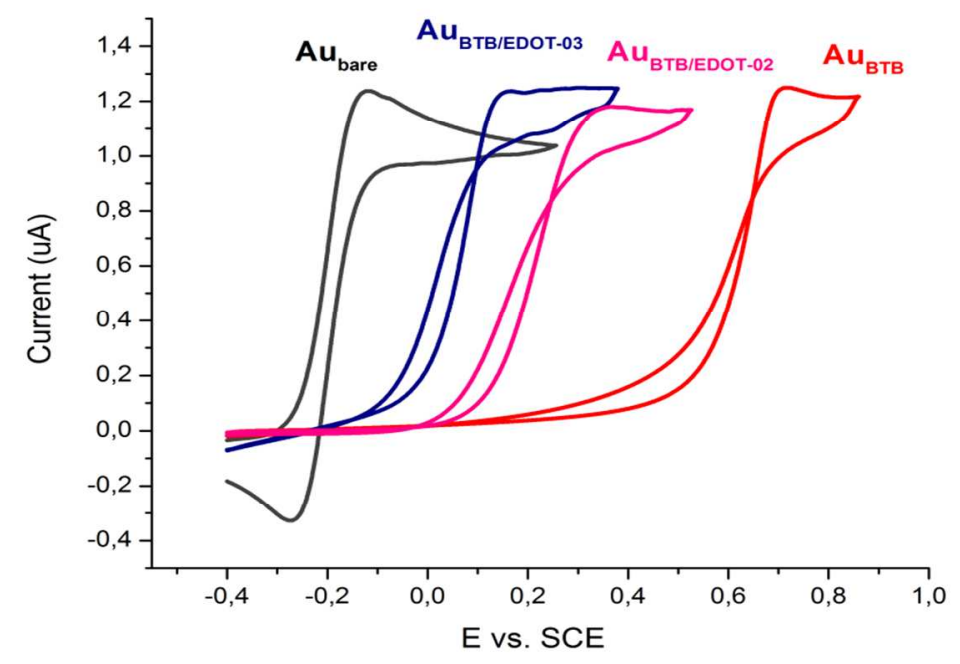

Figure 4: a) AFM profiles of a gold stripe covered with various organic layers. Bare gold, GoldBTB and Gold-BTB-EDOT1, Gold-BTB-EDOT2 and Gold-BTB-EDOT3 electrodes obtained by successive EDOT oxidation cycles at low current densities on the BTB-gold electrode. Note that the results reported here are obtained on a unique electrode that is modified in several successive steps. b) 3D AFM image of a Gold-BTB-EDOT3 electrode c) Response of ferrocene on the BTB-EDOT modified electrodes $(1 \mathrm{mM})$ with LiClO4 $(0.1 \mathrm{M})$ as supporting electrolyte in ACN, (d) Response of decamethylferrocene on the same BTB-EDOT modified electrodes $(1 \mathrm{mM})$ with $\mathrm{LiClO} 4(0.1 \mathrm{M})$ as supporting electrolyte in $\mathrm{ACN}$.

Overall, Scheme 2 summarizes the finding of this work. Starting from and $8 \mathrm{~nm}$ oligo(BTB) layer acting as a switchable electrode, it is possible to create a large set of new 
materials with tunable electrochemical properties. Oligo(EDOT) block of various length are grafted on the oligo(BTB) moieties leading to chain extension. As a consequence the new oligomers have higher energy HOMOs as seen in scheme $2 \mathrm{c}$ and the layer can switch from a conductive to insulating state at lower potential than the initial oligo(BTB) electrode. As long as the overall thickness remains below $11 \mathrm{~nm}$, the charge involved in the film electroactivity remains that of the initial oligo(BTB) layer with polaron, spreading over most of the oligomer ${ }^{40}$, likely localized on the growing EDOT blocl as depicted in Scheme 2b. Ultimately further growth will generate PEDOT chains on the electrodes as observed in figure SI3. This set of new material with tunable switching properties through a bottom-up electrochemical process leading to ultrathin layers with tailored switchable properties.
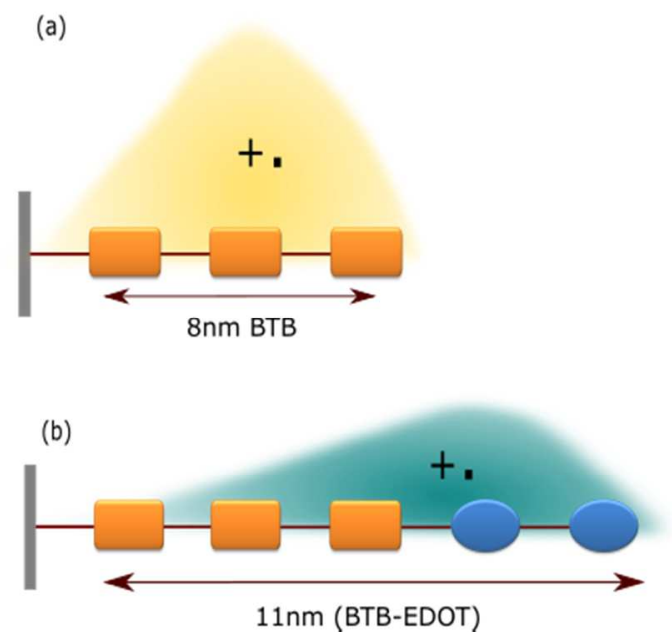

(c)

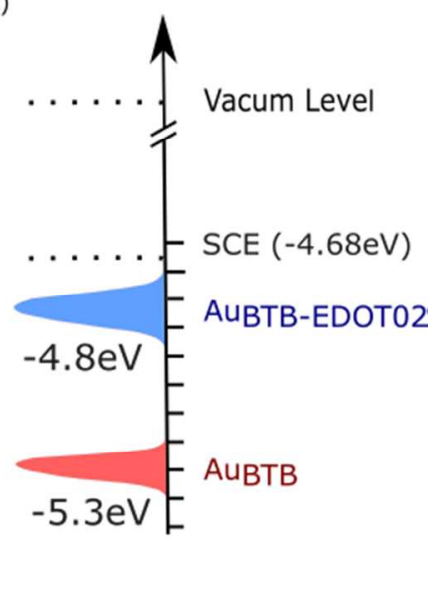

Scheme 2: Overall evolutions of the organic electrode properties while grafting $3 \mathrm{~nm}$ of oligo(EDOT) block on an $8 \mathrm{~nm}$ thick oligo(BTB) organic electrode. The yellow and green envelops represents the plausible extension a polaron on each oligomer.

\section{CONCLUSION}


In this work, focus was set towards extending the properties of ultrathin electroactive layers, based on oligo(BTB) layer, covalently attached to the electrode by diazonium salt reduction. Such layers switch from an insulating, to a conductive state and acts above their switching potential as organic electrodes This switch is strongly dependent on the molecular structure of the diazonium salt precursor. Here, EDOT oxidation was performed on ultrathin oligo(BTB) layers. We show first that EDOT can be easily oxidized on such organic electrode and that by using small current densities, EDOT oxidation does not generate PEDOT film on the oligo(BTB) layer but oligo(EDOT) oligomers grafted covalently on the oligo(BTB) units. As a consequence, new elongated oligomers with a block structure are generated on the surface. Moreover, the degree of elongation can be easily controlled as we observe successive switching potential decrease as a function of the EDOT overgrafting cycles, evidenced in voltammograms recorded in presence of several redox probes with different redox potentials. Depending on the length of the oligo(EDOT) block, the switching potential of the new layers can be tuned at will from 0.6 $\mathrm{V} / \mathrm{SCE}$ to $-0.3 \mathrm{~V} / \mathrm{SCE}$. As an exciting result, these large switching potential variations are obtained by grafting less than 3-4 nm of oligo(EDOT) on the oligo(BTB) layer.

Overall, a bottom-up electrochemical process for oligomer elongation is indeed possible and leads to thin films with very low switching potential being covalently grafted to the electrode surface. Furthermore, film switching potential can be fine-tuned to the desired potential, facilitating device fabrication. Finally, overgrafting electron withdrawing groups by a similar procedure, is likely to raise the switching potential of the layer instead of decreasing it, a feature which could enlarge even more the possibilities for tailoring film switching potentials to any desired potential. Such experiments are under investigation. 


\section{ASSOCIATED CONTENT}

Supporting Information. Comparison of Fc and DmFc response on oligo(BTB) modified electrodes and after cycling in EDOT solution after 1 and 7 EDOT overgrafting cycle, Evolution of $\mathrm{Q}_{\text {switch }}$ as a function of $\mathrm{Q}_{\text {deposition }}$ when. $\mathrm{Q}_{\text {deposition }}$ is above $7 \mathrm{mC} / \mathrm{cm}^{2}$. This material is available free of charge via the Internet at http://pubs.acs.org."

\section{AUTHOR INFORMATION}

\section{Corresponding Author}

* lacroix@univ-paris-diderot.fr

\section{Notes}

The authors declare no competing financial interest

\section{ACKNOWLEDGMENT}

This work was supported by the CNRS, the University Paris Diderot (Paris, France) and by a Ph.D. grant from the University of Science and Technology of Hanoi.

\section{REFERENCES}

1. Magasinski, A.; Dixon, P.; Hertzberg, B.; Kvit, A.; Ayala, J.; Yushin, G., Highperformance lithium-ion anodes using a hierarchical bottom-up approach. Nat Mater 2010, 9 (4), 353-358.

2. Godeau, G.; Darmanin, T.; Guittard, F., Switchable surfaces from highly hydrophobic to highly hydrophilic using covalent imine bonds. J Appl Polym Sci 2016, 133 (11), n/a-n/a.

3. Wang, J.; Li, J.; Li, N.; Guo, X.; He, L.; Cao, X.; Zhang, W.; He, R.; Qian, Z.; Cao, Y.; Chen, Y., A Bottom-Up Approach to Dual Shape-Memory Effects. Chem Mater 2015, 27 (7), 2439-2448.

4. Santos, L.; Martin, P.; Ghilane, J.; Lacaze, P. C.; Lacroix, J.-C., Micro/Nano-Structured Polypyrrole Surfaces on Oxidizable Metals as Smart Electroswitchable Coatings. ACS Applied Materials \& Interfaces 2013, 5 (20), 10159-10164. 
5. Lee, L.; Gunby, N. R.; Crittenden, D. L.; Downard, A. J., Multifunctional and Stable Monolayers on Carbon: A Simple and Reliable Method for Backfilling Sparse Layers Grafted from Protected Aryldiazonium Ions. Langmuir 2016, 32 (11), 2626-2637.

6. Lee, L.; Leroux, Y. R.; Hapiot, P.; Downard, A. J., Amine-Terminated Monolayers on Carbon: Preparation, Characterization, and Coupling Reactions. Langmuir 2015, 31 (18), 50715077.

7. Xu, L.; Chen, W.; Mulchandani, A.; Yan, Y., Reversible Conversion of Conducting Polymer Films from Superhydrophobic to Superhydrophilic. Angew Chem Int Ed 2005, 44 (37), 6009-6012.

8. Hermelin, E.; Petitjean, J.; Lacroix, J.-C.; Chane-Ching, K. I.; Tanguy, J.; Lacaze, P.-C., Ultrafast Electrosynthesis of High Hydrophobic Polypyrrole Coatings on a Zinc Electrode: Applications to the Protection against Corrosion. Chem Mater 2008, 20 (13), 4447-4456. 9. Wang, X.; Berggren, M.; Inganäs, O., Dynamic Control of Surface Energy and Topography of Microstructured Conducting Polymer Films. Langmuir 2008, 24 (11), 5942-5948. 10. Xu, L.; Wang, J.; Song, Y.; Jiang, L., Electrically Tunable Polypyrrole Inverse Opals with Switchable Stopband, Conductivity, and Wettability. Chem Mater 2008, 20 (11), 35543556.

11. Santos, L. M.; Ghilane, J.; Fave, C.; Lacaze, P. C.; Randriamahazaka, H.; Abrantes, L. M.; Lacroix, J. C., Electrografting polyaniline on carbon through the electroreduction of diazonium salts and the electrochemical polymerization of aniline. Journal of Physical Chemistry C 2008, 112, 16103-16109.

12. Nguyen, V.-Q.; Schaming, D.; Martin, P.; Lacroix, J.-C., Highly Resolved Nanostructured PEDOT on Large Areas by Nanosphere Lithography and Electrodeposition. ACS Applied Materials \& Interfaces 2015, 7 (39), 21673-21681.

13. Santos, L.; Ghilane, J.; Lacroix, J. C., Formation of Mixed Organic Layers by Stepwise Electrochemical Reduction of Diazonium Compounds. J Am Chem Soc 2012, 134 (12), 54765479.

14. Jacques, A.; Barthélémy, B.; Delhalle, J.; Mekhalif, Z., 1-Pyrrolyl-10decylammoniumphosphonate monolayer: a molecular nanolink between electropolymerized pyrrole films and nickel or titanium surfaces. Electrochim Acta 2015, 170, 218-228.

15. Lu, W.; Lieber, C. M., Nanoelectronics from the bottom up. Nat Mater 2007, 6 (11), 841850.

16. Love, J. C.; Estroff, L. A.; Kriebel, J. K.; Nuzzo, R. G.; Whitesides, G. M., SelfAssembled Monolayers of Thiolates on Metals as a Form of Nanotechnology. Chem Rev 2005, 105 (4), 1103-1170.

17. McCreery, R. L., Molecular Electronic Junctions. Chem Mater 2004, 16 (23), 4477-4496. 18. Sedghi, G.; García-Suárez, V. M.; Esdaile, L. J.; Anderson, H. L.; Lambert, C. J.; Martín, S.; Bethell, D.; Higgins, S. J.; Elliott, M.; Bennett, N.; Macdonald, J. E.; Nichols, R. J., Longrange electron tunnelling in oligo-porphyrin molecular wires. Nature nanotechnology 2011, 6 (July), 517-523.

19. Yan, H.; Bergren, A. J.; McCreery, R.; Della Rocca, M. L.; Martin, P.; Lafarge, P.; Lacroix, J. C., Activationless charge transport across 4.5 to $22 \mathrm{~nm}$ in molecular electronic junctions. Proc Natl Acad Sci U S A 2013, 110 (14), 5326-30.

20. Yuan, L.; Breuer, R.; Jiang, L.; Schmittel, M.; Nijhuis, C. a., A Molecular Diode with a Statistically Robust Rectification Ratio of Three Orders of Magnitude. Nano Lett 2015, $150721171048008-150721171048008$. 
21. Ho Choi, S.; Kim, B.; Frisbie, C. D., Electrical Resistance of Long Conjugated Molecular Wires. Science 2008, 320 (5882), 1482-1486.

22. Tran, E.; Duati, M.; Ferri, V.; Müllen, K.; Zharnikov, M.; Whitesides, G. M.; Rampi, M. A., Experimental Approaches for Controlling Current Flowing through Metal-Molecule-Metal Junctions. Adv Mater 2006, 18 (10), 1323-1328.

23. Tuccitto, N.; Ferri, V.; Cavazzini, M.; Quici, S.; Zhavnerko, G.; Licciardello, A.; Rampi, M. A., Highly conductive [sim]40-nm-long molecular wires assembled by stepwise incorporation of metal centres. Nat Mater 2009, 8 (1), 41-46.

24. Choi, S. H.; Risko, C.; Delgado, M. C. R.; Kim, B.; Brédas, J.-L.; Frisbie, C. D., Transition from Tunneling to Hopping Transport in Long, Conjugated Oligo-imine Wires Connected to Metals. J Am Chem Soc 2010, 132 (12), 4358-4368.

25. McCreery, R. L.; Yan, H.; Bergren, A. J., A critical perspective on molecular electronic junctions: there is plenty of room in the middle. PCCP 2013, 15 (4), 1065-1081.

26. Martin, P.; Della Rocca, M. L.; Anthore, A.; Lafarge, P.; Lacroix, J.-C., Organic

Electrodes Based on Grafted Oligothiophene Units in Ultrathin, Large-Area Molecular Junctions. J Am Chem Soc 2012, 134 (1), 154-157.

27. Sayed, S. Y.; Bayat, A.; Kondratenko, M.; Leroux, Y.; Hapiot, P.; McCreery, R. L., Bilayer Molecular Electronics: All-Carbon Electronic Junctions Containing Molecular Bilayers Made with "Click" Chemistry. J Am Chem Soc 2013, 135 (35), 12972-12975.

28. Fave, C.; Leroux, Y.; Trippé, G.; Randriamahazaka, H.; Noel, V.; Lacroix, J.-C., Tunable Electrochemical Switches Based on Ultrathin Organic Films. J Am Chem Soc 2007, 129 (7), 1890-1891.

29. Fave, C.; Noel, V.; Ghilane, J.; Trippé-Allard, G.; Randriamahazaka, H.; Lacroix, J. C., Electrochemical Switches Based on Ultrathin Organic Films: From Diode-like Behavior to Charge Transfer Transparency. J. Phys. Chem. C 2008, 112 (47), 18638-18643.

30. Stockhausen, V.; Trippé-Allard, G.; Van Quynh, N.; Ghilane, J.; Lacroix, J.-C., Grafting $\pi$-Conjugated Oligomers Incorporating 3,4-Ethylenedioxythiophene (EDOT) and Thiophene Units on Surfaces by Diazonium Electroreduction. J. Phys. Chem. C 2015, 119 (33), 1921819227.

31. Stockhausen, V.; Ghilane, J.; Martin, P.; Trippé-Allard, G.; Randriamahazaka, H.; Lacroix, J.-C., Grafting Oligothiophenes on Surfaces by Diazonium Electroreduction: A Step toward Ultrathin Junction with Well-Defined Metal/Oligomer Interface. J Am Chem Soc 2009, 131 (41), 14920-14927.

32. Trippé-Allard, G.; Lacroix, J.-C., Synthesis of nitro- and amino-functionalized $\pi$ conjugated oligomers incorporating 3,4-ethylenedioxythiophene (EDOT) units. Tetrahedron 2013, 69 (2), 861-866.

33. Doyle, M. P.; Bryker, W. J., Alkyl nitrite-metal halide deamination reactions. 6. Direct synthesis of arenediazonium tetrafluoroborate salts from aromatic amines, tert-butyl nitrite, and boron trifluoride etherate in anhydrous media. The Journal of Organic Chemistry 1979, 44 (9), 1572-1574.

34. Delamar, M.; Hitmi, R.; Pinson, J.; Saveant, J. M., Covalent modification of carbon surfaces by grafting of functionalized aryl radicals produced from electrochemical reduction of diazonium salts. J Am Chem Soc 1992, 114 (14), 5883-5884.

35. Baranton, S.; Bélanger, D., In situ generation of diazonium cations in organic electrolyte for electrochemical modification of electrode surface. Electrochim Acta 2008, 53 (23), 69616967. 
36. Fluteau, T.; Bessis, C.; Barraud, C.; Della Rocca, M. L.; Martin, P.; Lacroix, J.-C.; Lafarge, P., Tuning the thickness of electrochemically grafted layers in large area molecular junctions. J Appl Phys 2014, 116 (11), 114509.

37. Amatore, C.; Savéant, J. M.; Tessier, D., Charge transfer at partially blocked surfaces. Journal of Electroanalytical Chemistry and Interfacial Electrochemistry 1983, 147 (1), 39-51. 38. LaCroix, J. C.; Diaz, A. F., Electrolyte Effects on the Switching Reaction of Polyaniline. J Electrochem Soc 1988, 135 (6), 1457-1463.

39. Dung Nguyen, T.; Camalet, J. L.; Lacroix, J. C.; Aeiyach, S.; Pham, M. C.; Lacaze, P. C., Polyaniline electrodeposition from neutral aqueous media: Application to the deposition on oxidizable metals. Synth Met 1999, 102 (1), 1388-1389.

40. Lacroix, J. C.; Chane-Ching, K. I.; Maquère, F.; Maurel, F., Intrachain Electron Transfer in Conducting Oligomers and Polymers: The Mixed Valence Approach. J Am Chem Soc 2006, $128(22), 7264-7276$.

\section{Insert Table of Contents Graphic and Synopsis Here}
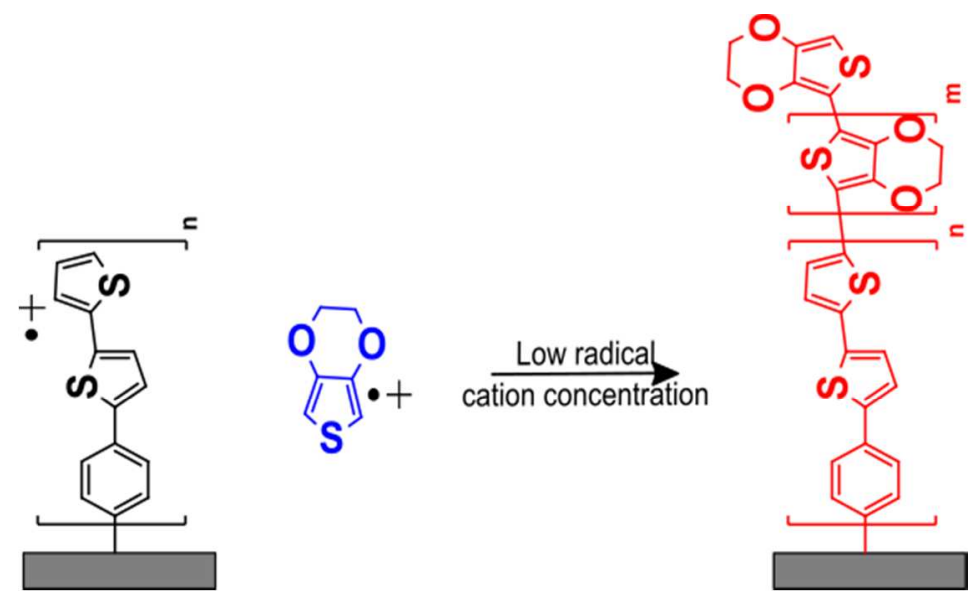